\title{
Towards the total synthesis of Trichormamide A, a cyclic undecapeptide.
}

\author{
Michel Gaillard ${ }^{\mathrm{a}}$, Sanjit Das ${ }^{\mathrm{a},}$, Mahamadou Djibo ${ }^{\mathrm{a}}$, Delphine Raviglione ${ }^{\mathrm{a}}$, Christian Roumestand ${ }^{\mathrm{b}}$, Baptiste \\ Legrand $^{\mathrm{c}}$ and Nicolas Inguimbert ${ }^{\mathrm{a},}{ }^{*}$ \\ ${ }^{a}$ USR 3278 CRIOBE, PSL Research University, EPHE-UPVD-CNRS, Université de Perpignan Via Domitia, Laboratoire d'Excellence «CORAIL ». Bâtiment T, \\ 58 avenue P. Alduy, 66860 Perpignan, France. E-mail: nicolas.inguimbert@univ-perp.fr \\ ${ }^{b}$ Centre de Biochimie Structurale (CBS), Univ Montpellier, CNRS, UM, INSERM, Montpellier, France. \\ ${ }^{c}$ Institut des Biomolécules Max Mousseron (IBMM), Univ Montpellier, CNRS, UM, ENSCM, Montpellier, France.
}

Lipocyclopeptides isolated from marine sources hold great promise as new lead for therapeutics. Here, we propose the first attempt towards the total synthesis of Trichormamide A. This synthesis will help to confirm the proposed structure of the cyclic lipopeptide.

\section{Introduction}

With an aging global population global, the 21 st century is facing new challenges with respect to cancer, neurodegenerative and cardiovascular diseases. Multidisciplinary projects around the world are directed towards the identification of new leads in order to address these problems. Natural products that have played a crucial role in the discovery of new drugs for the treatment of a wide spectrum of therapeutic disorders may provide possible sources for solutions to be discovered. ${ }^{1}$ In the last 70 -years, among the 175 cancer chemotherapy drugs in clinical use, $49 \%$ were obtained directly from natural substances or from modified natural molecules. ${ }^{2}$ Over the past twenty years, interest in natural compounds has diminished and most large pharmaceutical companies have stopped their natural product programs to focus on combinatorial chemistry and other less expensive approaches. Combinatorial chemistry has yielded disappointing results and there is increasing pressure to revisit natural sources as a source of new pharmaceutical molecules. ${ }^{3,4,5}$ Microorganisms and cyanobacteria of terrestrial and marine habitats are of special interest and their ability to produce secondary metabolites can be examined through metabolomics which enables the identification of compounds in complex mixtures. ${ }^{6}$ This is helped by pre-fractionation strategies focused on compounds of medium range lipophilicity, the most polar and hydrophobic fractions being discarded thus reducing the chemical complexity of natural extracts. This strategy increased the success rate of high-throughput-screening processes which lead to a more efficacious identification of bioactive compounds. ${ }^{7}$ This general method was applied to terrestrial and marine filamentous cyanobacteria that constitute a prolific source of secondary metabolites with possible therapeutic applications. ${ }^{8,9,10}$ A majority of these compounds are peptides and polyketides characterized by a high degree of chemical diversity thanks to their biosynthesis which relies on non-ribosomal peptide synthase or/and polyketide synthase. ${ }^{11}$ For example, the Anabaena torulosa, Anabaena laxa, Hormothamnion enteromorphoides, Trichormus sp, Lyngbya confervoides and oscillatoria sp strains produced laxaphycins, ${ }^{12,13,14}$ hormothamnins, ${ }^{15,16}$

lobocyclamides, ${ }^{17}$ trichormamides ${ }^{18,19}$ and lyngbyacyclamides. ${ }^{20}$ Despite having different names these compounds are closely related and can be distinguished as laxaphycins of types A and B (LaxA and B) which are cyclic undeca- or dodeca-peptides containing a $\beta$-amino acid with a linear chain of up to 12 carbons, respectively (Figure 1). The two types have often been coisolated and LaxB was shown to be ten times more potent than LaxA leading to the hypothesis of a synergic biological effect that was highlighted on cancer cell lines, but still remains not fully understood. ${ }^{21,14}$ While relatively homogeneous in terms of structure the trichormamide A ( TcA) constituted an exception as it does not possess the Dhb amino acid, nor homoserine or Dallo-Ile in its sequence (Figure 1). This exception made TcA an ideal candidate for the development of a synthesis that could later be extended to the other members of the LaxA family. Herein we have described the synthesis of TcA. The developed synthetic route was sufficiently robust and allowed for the addition of a diastereomer where an isoleucine was replaced by a D-alloisoleucine, a configuration typical of other LaxA analogues. 


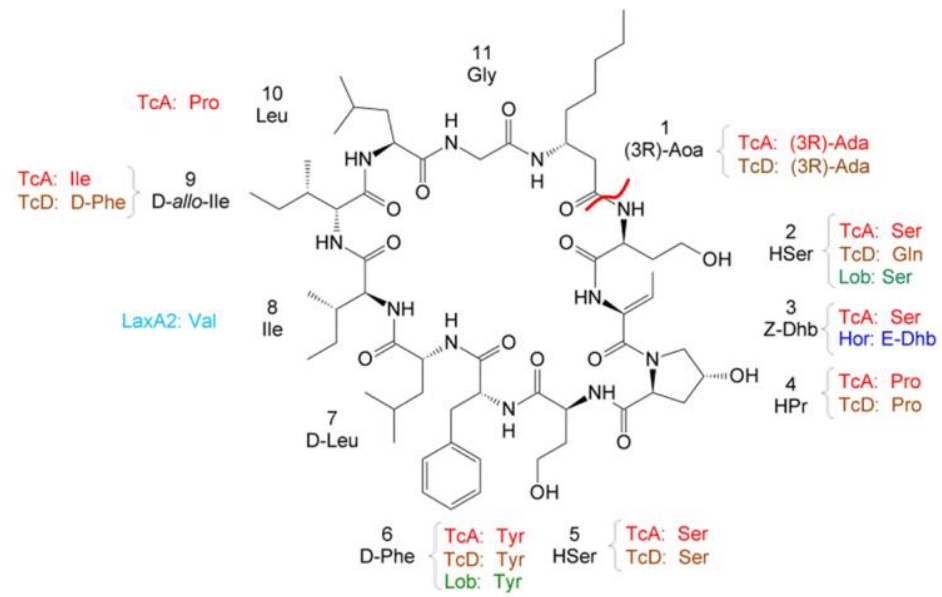

Laxaphycin A-type

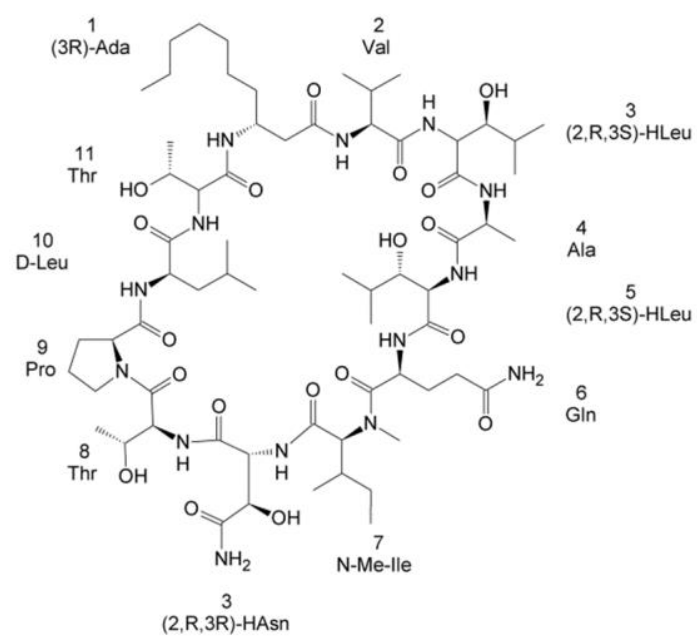

Laxaphycin B

Figure 1. Structures of laxaphycin A and laxaphycin B. Variability of the laxaphycin A type sequence are indicated. Trichormamides A and B, laxaphycin A2, lobocyclamide, hormothamnin are abbreviated TcA, TcB, LaxA2, Lob and Hor, respectively. Red curved line indicated disconnection point on laxaphycin A.

\section{Results and discussion}

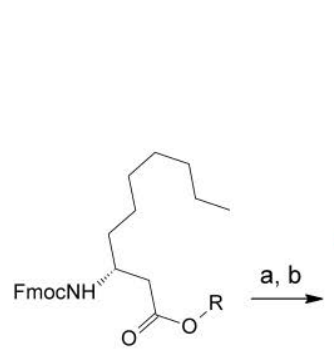

$1 \mathrm{R}:$ 2-Cl-Trt-resin

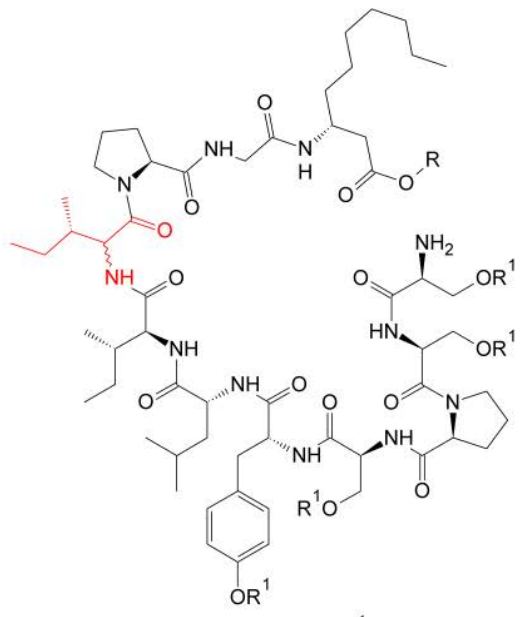

2a R: 2-Cl-Trt-resin; $\mathrm{R}^{1}=t \mathrm{Bu}$; Ile
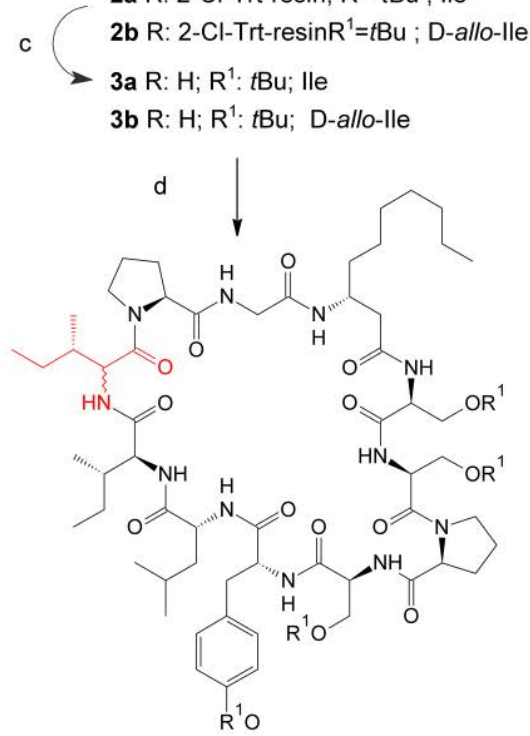

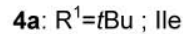

4b: $R^{1}=t B u ; D-a l l o-l l e$

e

$5 \mathrm{a}: \mathrm{R}^{1}=\mathrm{H} ; \| \mathrm{l}$

5b: $\mathrm{R}^{1}=\mathrm{H} ; \mathrm{D}$-allo-lle

Figure 2. Synthesis of TCA $\mathbf{5 a}$ and its analogues $\mathbf{5 b}$. a: piperidine; b: DIC/Oxyma FmocAAOH; c: TFE, AcOH ; d:PyOxym/Oxyma; e: TFA.

In comparison with our previous laxB synthesis that was performed entirely with an SPPS protocol, ${ }^{22,23} \mathrm{TcA}$ was

assembled on a 2-Cl trityl-resin and cyclization was performed in solution Among the possible disconnections that will reduce the risk of isomerization, anchoring Ada on the resin is very attractive as it saves this rare amino acid, synthesized using a reported procedure. ${ }^{24}$ Consequently, the synthesis of trichormamide A (TcA) was performed at a $0.1 \mathrm{mmol}$ scale on a 2-Cl trityl resin preloaded with Fmoc-Ada 1. The resin loading was estimated at $0.69 \mathrm{mmol} / \mathrm{g}$ after Fmoc cleavage using 2\% of DBU in DMF. ${ }^{25}$ Stepwise addition of the amino acids constituting the TcA was performed using five equivalents of amino acids in the presence of a mixture of DIC/Oxyma as coupling reagents. In order to avoid premature cleavage of the peptide from the 2-Cl trityl resin, the temperature was lowered to $50^{\circ} \mathrm{C}$ through microwave irradiation. ${ }^{26}$ After completion, the on resin linear precursors $\mathbf{2} \mathbf{a}$ and $\mathbf{2} \mathbf{b}$ were cleaved from the resin with a DCM/TFE/AcOH 8/1/1 mixture. An LC/MS analysis of the crudes attests for the presence of compounds $\mathbf{3 a}$ and $\mathbf{3 b}$ with a molecular peak at $\mathrm{m} / \mathrm{z}: 1426.42$ and $\mathrm{m} / \mathrm{z}: 1426.28$, respectively. Cyclization of compounds 3a-b was accomplished with PyOxym/Oxyma under pseudo-high dilution conditions, as previously reported, affording compounds $\mathbf{4 a - b}$ with molecular peak at $m / z$ : 1408.7 (Supporting information Figure S1a). ${ }^{27}$ Compounds $\mathbf{4 a - b}$ were purified prior to the deprotection of side chains. Acidic removal of the tertio-butyl groups followed by HPLC purification afforded about $10 \mathrm{mg}$ of compounds $\mathbf{5 a}-\mathbf{b}$ as white powder (Figure 2).

LC/ MS analysis revealed that the retention times of $\mathbf{5 a}(7.7 \mathrm{~min})$ and $\mathbf{5 b}$ (13.3 $\mathrm{min})$ are significantly different even if they differ only by the stereochemistry at the $\alpha$-carbon of Ile $^{9}$ (Figure S1b). Compounds $\mathbf{5 a}$ and $\mathbf{5 b}$ are characterized in HRESI-MS by molecular peaks analysis at $m / z: 1184.6919$ and 1184.6877 in the positive mode and 1182.6788 and 1182.6722 in the negative mode, respectively (Figures S2). The observed ions fall in the 5 ppm range admitted for accurate mass determination for a peptide with a molecular formula of $\mathrm{C}_{58} \mathrm{H}_{93} \mathrm{~N}_{11} \mathrm{O}_{15}$ (Calculated mass $[\mathrm{M}+\mathrm{H}]^{+}:$1184.6931 and $\left.[\mathrm{M}-\mathrm{H}]-: 1182.6774\right) .{ }^{28}$ This result was further confirmed by fragmentation of the parent ion using $70 \mathrm{eV}$ collision energy in the positive and negative modes. In the positive mode, dehydration of two and three serines gave the following ions: $\mathrm{m} / \mathrm{z}$ : 1148.6688, 1130.6582 (Figure 3A and Figures S6-S7). A similar phenomenon is observed in the negative mode where deprotonation of the three serines lead to the release of formaldehyde and formation of subsequent ion 7 at $m / z: 1092.6473$. (Figures 3B and S3). ${ }^{29,30}$ Thus the observed fragmentation pattern confirmed the presence of the three serines in the synthesized compounds $\mathbf{5 a}$ and $\mathbf{5 b}$. The obtained ions undergo further fragmentation allowing the correctness of the sequence to be assessed. 

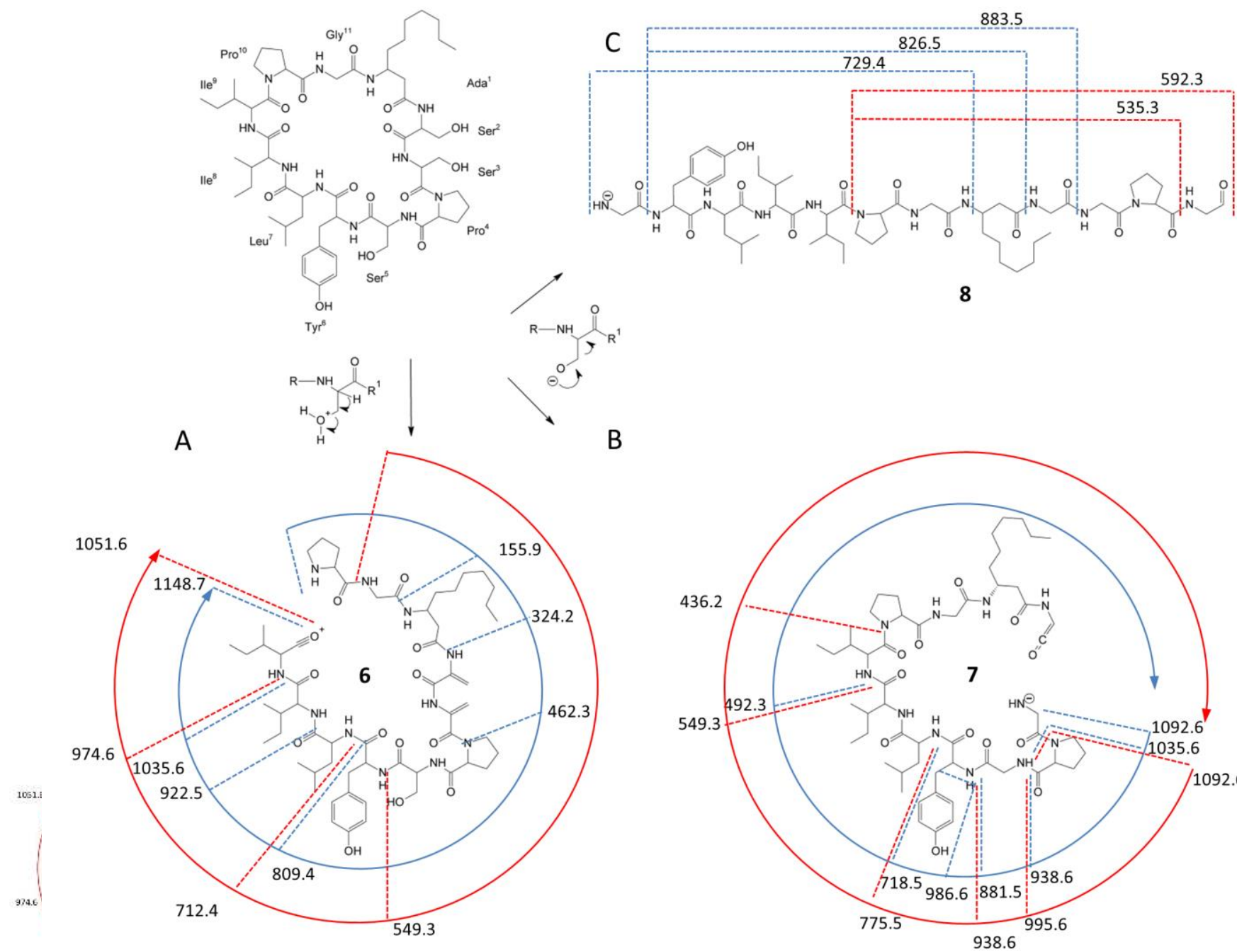

8

B

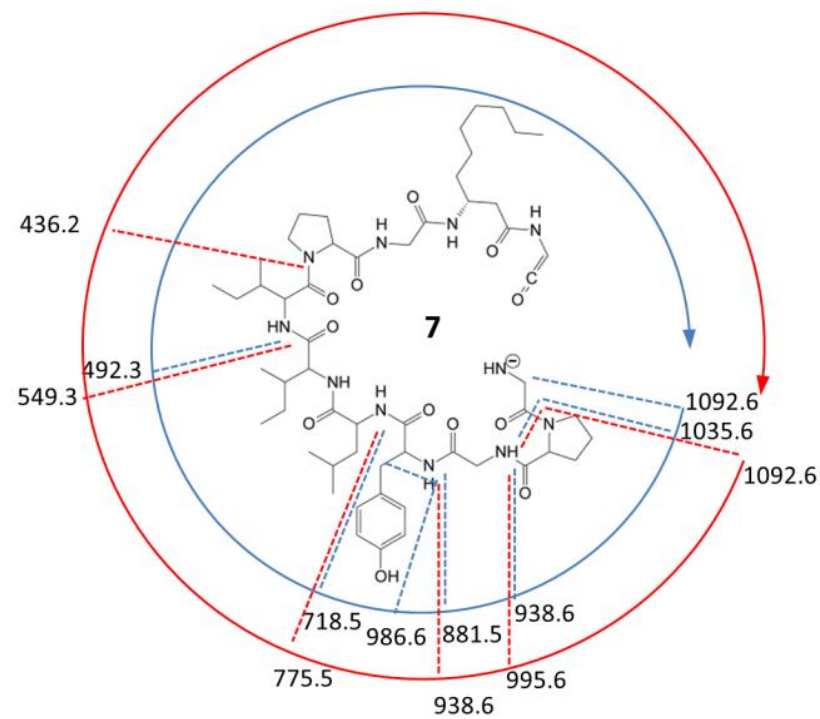

Figure 3. Collision induced dissociation of $5 \mathrm{a} 1$ generating parent ions 6 and 7 throughout dehydration and deformylation mechanisms, respectively. A. Selected CID fragments observed for $\mathbf{6}$ in positive mode. B and C. Selected CID fragments observed for 7 and $\mathbf{8}$ in negative mode.

In the positive mode fragmentation is initiated at the $\mathrm{Ile}^{9} \mathrm{Pro}^{10}$ or Pro ${ }^{10} \mathrm{Gly}^{11}$ amide bonds. The two parent ions 6 deliver different $\mathrm{b}$ ions consistent with the peptide sequence (Figure $3 \mathrm{~A}$ ). ${ }^{31,32}$ Nevertheless, attribution of all fragments cannot be achieved because of the concomitance between dehydrated forms occurring from serine and induced rearrangements. In the negative mode, the most intense observed ions arose from the fragmentation of the parent ion 7 at $m / z$ : 1092.6473 which deliver after breakage at the $\mathrm{Ser}^{3}-\mathrm{Pro}^{4}$ amide bond an intense ion at $\mathrm{m} / \mathrm{z}$ : 938.5726 by loss of Gly and Pro. Fragmentation of the same ion induced the loss of a tyrosine side chain and formation of a $\gamma$ ion with $m / z$ : 986.6059 . Successive loss of amino acids starting from 7 at $m / z$ : 1092.6473 produced $\beta$ ions of low intensity, albeit ions with higher intensities are observed when the fragment is common to other fragmentation pathways such as the one observed at $\mathrm{m} / z$ : 938.5735 (Figure 3B). The most intense fragments observed with negative ESI arose from splitting of the unusual fragment 8, (Figure 3C).

1D ${ }^{1} \mathrm{H}$ and 2D-homonuclear COSY, TOCSY, ROESY and ${ }^{13} \mathrm{C}$ $\mathrm{HSQC}$ heteronuclear NMR spectra were recorded in $\mathrm{CD}_{3} \mathrm{OH}$ at $300 \mathrm{~K}$ to further confirm the structure of the synthesized compounds $\mathbf{5 a}$ and $\mathbf{5 b}$. Nearly all resonances could be assigned unambiguously (Table 1). The signal pattern was compatible with a lipopeptide containing a tyrosine residue with characteristic doublets $\left(\delta_{\mathrm{H}} 7.11, J=8.3 \mathrm{~Hz}\right.$ and $6.67, J=8.3 \mathrm{~Hz}$ for $\mathbf{5 a}$ and $\delta_{\mathrm{H}}$ $7.10, J=8.5 \mathrm{~Hz}$ and $6.68, J=8.5 \mathrm{~Hz}$ for $\mathbf{5 b})$, amide protons $\left(\delta_{\mathrm{H}}\right.$ 7.5-8.5 ppm), $\alpha$-protons $\left(\delta_{\mathrm{H}} 4.2-4.7 \mathrm{ppm}\right)$, methylene protons (1.2-4.9 ppm) and methyl signals (0.8-1 ppm). The different serine and isoleucine were readily identified and the presence of the $\beta$-aminodecanoic acid was confirmed. Only a few signals could not be assigned for $\mathbf{5 b}$ due to signal superimpositions or line broadening (Table 1, Figures S5-10).

In summary, we synthesized two lipocyclopeptides whose sequences correspond to the previously reported TcA sequence and to a possible diastereomer in which the $\mathrm{Ile}^{9}$ was replaced by the more frequently found allo-Ile characteristic of the other representatives of the laxaphycin A family (Figure 1). While the recorded HRMS from 5a-b converged with the mass that was determined for the previously reported natural compound, the NMR experiments showed significant differences. Indeed, while the amide region showed very sharp and defined peaks for the natural compounds those of the synthetic compounds $\mathbf{5 a - b}$ are less defined and separated even if the compounds were analyzed using similar spectrometers and in the same solvents. As it was impossible to rule out that an error had occurred during the preparation of $\mathbf{5 a}$, a second synthesis of compound $\mathbf{5 a}$ was run for verification purposes. The obtained compound $\mathbf{5 a 2}$, as expected, shares the same retention time, HRMS peaks and ${ }^{1} \mathrm{H}$ NMR spectra as the one obtained during the first attempt, thus reconfirming the accuracy of the sequence derived from the synthesis (Figures S1 and S10-19). Unfortunately, without a supply of the natural compound for comparative purposes, the structure could not be definitively confirmed. As such, we cannot exclude the possibility that the reported TcA has a planar structure that is isobaric from the one reported in this study for 5a-b. ${ }^{33}$ 
Table 1. NMR data for $\mathbf{5 a}-\mathbf{b}$ in $\mathrm{CD}_{3} \mathrm{OH}\left(600 \mathrm{MHz}\right.$ for ${ }^{1} \mathrm{H}$ and $150 \mathrm{MHz}$ for ${ }^{13} \mathrm{C}$ NMR data $)$

\begin{tabular}{|c|c|c|c|c|c|c|}
\hline & & $5 \mathbf{a}$ & & $5 b$ & & \\
\hline & $\mathrm{C} / \mathrm{Hn}^{\circ}$ & $\delta_{\mathrm{C}}$ & $\delta_{\mathrm{H}}$ & $\delta_{\mathrm{C}}$ & $\delta_{\mathrm{H}}$ & Observed 2D NMR correlations of compounds $\mathbf{5 a}$ and $\mathbf{5 b}$ \\
\hline \multirow[t]{11}{*}{$\beta$-Ada ${ }^{1}$} & 1 & 174.2 & & $n d$ & & \\
\hline & 2 & 42.1 & $2.36,2.60$ & 42.1 & $2.15,2.50$ & \\
\hline & 3 & 48.7 & 4.21 & 46.8 & 4.38 & \\
\hline & 4 & 35.4 & $1.38,1.56$ & 34.9 & $1.58,1.54$ & \\
\hline & 5 & 33.0 & 1.25 & 31.7 & 1.26 & \\
\hline & 6 & 30.7 & 1.26 & 29 & 1.28 & 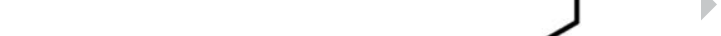 \\
\hline & 7 & 30.4 & 1.19 & 25 & 1.33 & \\
\hline & 8 & 23.7 & 1.27 & 22.3 & 1.30 & \\
\hline & 9 & 23.7 & 1.27 & 22.3 & 1.30 & \\
\hline & 10 & 14.4 & 0.86 & 12.7 & 0.88 & \\
\hline & $\mathrm{NH}$ & & 7.92 & & 7.60 & \\
\hline \multirow[t]{5}{*}{$\operatorname{Ser}^{2}$} & 1 & $n d$ & & $n d$ & & \\
\hline & 2 & 58.7 & 4.37 & 55.1 & 4.56 & \\
\hline & 3 & 62.4 & $3.96,3.86$ & 61.9 & $3.86,3.81$ & \\
\hline & $\mathrm{NH}$ & & 8.20 & & 7.63 & \\
\hline & $\mathrm{OH}$ & & 5.67 & & 5.26 & \\
\hline \multirow[t]{4}{*}{$\mathrm{Ser}^{3}$} & 1 & nd & & nd & & \\
\hline & $\begin{array}{l}2 \\
3\end{array}$ & $\begin{array}{l}55.4 \\
63.6\end{array}$ & $\begin{array}{l}4.94 \\
3.86,4.05\end{array}$ & $\begin{array}{l}n d^{a} \\
61.2\end{array}$ & $\begin{array}{l}4.75 \\
4.08,3.91\end{array}$ & \\
\hline & $\mathrm{NH}$ & & 8.15 & & nd & \\
\hline & $\mathrm{OH}$ & & 5.62 & & 5.79 & \\
\hline \multirow[t]{4}{*}{$\mathrm{Pro}^{4}$} & 1 & 172.2 & & & & \\
\hline & $\begin{array}{l}2 \\
3\end{array}$ & $\begin{array}{l}63.2 \\
30.3\end{array}$ & $\begin{array}{l}4.50 \\
1.93,2.35\end{array}$ & 61.9 & $\begin{array}{l}4.44 \\
2.39\end{array}$ & \\
\hline & 4 & 26.3 & $1.99,2.07$ & 28.9 & $1.95,2.06$ & \\
\hline & 5 & 49.0 & $3.83,3.88$ & 47.6 & 3.90 & \\
\hline \multirow[t]{5}{*}{$\operatorname{Ser}^{5}$} & 1 & $n d$ & & $n d$ & & \\
\hline & 2 & 56.7 & 4.32 & 54.7 & 4.39 & \\
\hline & 3 & 62.5 & $3.73,3.68$ & 60.8 & 3.78 & SY - TOCSY \\
\hline & $\mathrm{NH}$ & & 7.76 & & 7.56 & ROESY \\
\hline & $\mathrm{OH}$ & & 5.35 & & 5.27 & HMBC \\
\hline \multirow[t]{9}{*}{ Tyr $^{6}$} & 1 & 174.1 & & $n d$ & & \\
\hline & 2 & 56.9 & 4.46 & 58.1 & 4.51 & 5. \\
\hline & 3 & 38.6 & $2.92,3.00$ & 36.7 & 3.00 & $5 \mathbf{a}$ \\
\hline & 4 & 127.7 & & & & \\
\hline & 5 & 131.3 & 7.11 & 130.1 & 7.10 & \\
\hline & 6 & 115.0 & 6.67 & 114.9 & 6.68 & \\
\hline & 7 & 156.0 & & & & \\
\hline & $\mathrm{NH}$ & & 7.70 & & 7.69 & \\
\hline & $\mathrm{OH}$ & & 9.03 & & 9.01 & \\
\hline \multirow[t]{6}{*}{$\mathrm{Leu}^{7}$} & 1 & 173.8 & & nd & & \\
\hline & 2 & 53 & 4.43 & 52.4 & 4.40 & \\
\hline & 3 & 41.3 & $1.52,1.61$ & 39.5 & $1.58,1.44$ & \\
\hline & 4 & 25.8 & 1.56 & 24.6 & 1.59 & \\
\hline & 5 & $22.5,23.2$ & $0.89,0.92$ & $20,22.2$ & $0.88,0.86$ & \\
\hline & $\mathrm{NH}$ & & 8.26 & & 7.85 & \\
\hline \multirow[t]{6}{*}{$\mathrm{Ile}^{8}$} & 1 & 173.9 & & $n d$ & & \\
\hline & 2 & 59.4 & 4.27 & 58.0 & 4.51 & \\
\hline & 3 & 37.3 & 1.91 & 36.0 & 2.00 & \\
\hline & 3-Me & 16.3 & 0.96 & 15.0 & 0.96 & \\
\hline & $\begin{array}{l}4 \\
5\end{array}$ & 27.3 & $1.82,1.21$ & 25.8 & $1.50,1.19$ & \\
\hline & $\mathrm{NH}$ & 11.3 & $\begin{array}{l}0.92 \\
8.16\end{array}$ & 10.3 & 7.68 & \\
\hline \multirow[t]{7}{*}{$\mathrm{Ile}^{9}$} & 1 & 173.9 & & $n d$ & & \\
\hline & 2 & 59.4 & 4.26 & 54.9 & 4.68 & \\
\hline & 3 & 36.4 & 1.90 & 36.0 & 2.00 & \\
\hline & $3-\mathrm{Me}$ & 15.8 & 0.86 & 14.1 & 0.98 & \\
\hline & 4 & 26.9 & $1.69,1.12$ & 26.1 & $1.44,1.22$ & \\
\hline & 5 & 10.8 & 0.89 & 10.5 & 0.89 & \\
\hline & $\mathrm{NH}$ & & 8.25 & & 8.53 & \\
\hline \multirow[t]{5}{*}{$\operatorname{Pro}^{10}$} & 1 & 174.9 & & $n d$ & & \\
\hline & 2 & 63.0 & 4.20 & 61.2 & 4.24 & \\
\hline & 3 & 29.6 & $2.15,1.85$ & 28.9 & $2.24,1.98$ & COSY - TOCSY \\
\hline & 4 & 26.6 & $1.89,2.05$ & 24.9 & 2.15 & ROESY \\
\hline & 5 & 48.4 & $3.73,3.67$ & 47.9 & $3.78,3.74$ & \\
\hline \multirow[t]{3}{*}{ Gly $^{11}$} & 1 & 170.7 & & $n d$ & & $5 b$ \\
\hline & 2 & 43.8 & $3.50,3.97$ & 42.6 & $3.82,3.87$ & \\
\hline & $\mathrm{NH}$ & & 8.46 & & 8.06 & \\
\hline
\end{tabular}

${ }^{a} n d$ not determined

\section{Acknowledgments}

The spectroscopic experiments were performed at the "Laboratoire de mesures physiques" (LMP) at the University of 
Montpellier and at the Biodiversité et Biotechnologies Marines facilities (Bio2Mar, http://bio2mar.obs-banyuls.fr/fr/index.html) at the University of Perpignan. C Roumestand is supported by the French Infrastructure for Integrated Structural Biology (FRISBI) ANR-10-INBS-05. We are grateful to our American colleague J Almany for comments and carefully proofreading of the manuscript.

\section{References and notes}

1. Newman DJ, Cragg GM. J Nat Prod. 2012; 75: 311-335.

2. Rayan A, Raiyn J, Falah M. PLOS ONE. 2017; 12: e0187925.

3. Surowiecki J. New Yorker, 2004, 80, 72.

4. David B, Wolfender J-L, Dias DA. Phytochem Rev. 2015; 14: 299-315.

5. Shen B. Cell. 2015; 163: 1297-1300.

6. Harvey AL, Edrada-Ebel R, Quinn RJ. Nat Rev Drug Discov. 2015; 14 : 111-129.

7. Thornburg CC, Britt JR, Evans JR, Akee RK, Whitt JA, Trinh SK, Harris MJ, Thompson JR, Ewing TL, Shipley SM, Grothaus PG, Newman DJ, Schneider JP, Grkovic T, O'Keefe BR. ACS Chem Biol. 2018

8. Burja AM, Banaigs B, Abou-Mansour E, Grant Burgess J, Wright PC. Tetrahedron. 2001; 57: 9347-9377.

9. Esquenazi E, Coates C, Simmons L, Gonzalez D, Gerwick WH, Dorrestein PC. Mol Biosyst. 2008; 4: 562-570.

10. Banaigs B, Bonnard I, Witczak A, Inguimbert N. In Outstanding Marine Molecules; S. L. Barre, and J.-M. Kornprobst, Eds.; WileyVCH Verlag GmbH \& Co. KGaA, 2014; pp 285-318.

11. Nunnery JK, Mevers E, Gerwick WH. Curr Opin Biotechnol. 2010; 21: 787-793

12. Frankmölle WP, Knübel G, Moore RE, Patterson GM. J Antibiot (Tokyo). 1992; 45: 1458-1466.

13. Bonnard I, Rolland M, Francisco C, Banaigs B. Lett Pept Sci. 1997; 4: 289-292.

14. Cai W, Matthew S, Chen Q-Y, Paul VJ, Luesch H. Bioorg Med Chem 2018; 26: 2310-2319.

15. Gerwick WH, Mrozek C, Moghaddam MF, Agarwal SK. Experientia. 1989; 45: 115-121.

16. Gerwick WH, Jiang ZD, Agarwal SK, Farmer BT. Tetrahedron. 1992; 48: 2313-2324.

17. MacMillan JB, Ernst-Russell MA, de Ropp JS, Molinski TF. J Org Chem. 2002; 67: 8210-8215.

18. Luo S, Krunic A, Kang H-S, Chen W-L, Woodard JL, Fuchs JR, Swanson SM, Orjala J. J Nat Prod. 2014; 77: 1871-1880.

19. Luo S, Kang H-S, Krunic A, Chen W-L, Yang J, Woodard JL, Fuchs JR, Hyun Cho S, Franzblau SG, Swanson SM, Orjala J. Bioorg Med Chem. 2015; 23: 3153-3162.

20. Maru N, Ohno O, Uemura D. Tetrahedron Lett. 2010; 51: 6384-6387.

21. Bonnard I, Rolland M, Salmon J-M, Debiton E, Barthomeuf C, Banaigs B. J Med Chem. 2007; 50: 1266-1279.

22. Boyaud F, Mahiout Z, Lenoir C, Tang S, Wdzieczak-Bakala J, Witczak A, Bonnard I, Banaigs B, Ye T, Inguimbert N. Org Lett. 2013; 15: 3898-3901.

23. Bornancin L, Boyaud F, Mahiout Z, Bonnard I, Mills SC, Banaigs B, Inguimbert N. Mar Drugs. 2015; 13: 7285-7300.

24. Buron F, Turck A, Plé N, Bischoff L, Marsais F. Tetrahedron Lett. 2007; 48: 4327-4330.

25. Gude M, Ryf J, White PD. Lett Pept Sci. 2002; 9: 203-206.

26. Echalier C, Al-Halifa S, Kreiter A, Enjalbal C, Sanchez P, Ronga L, Puget K, Verdié P, Amblard M, Martinez J, Subra G. Amino Acids. 2013; 45: 1395-1403.

27. Malesevic M, Strijowski U, Bächle D, Sewald N. J Biotechnol. 2004; 112: 73-77.

28. Pleil JD, Isaacs KK. J Breath Res. 2016; 10: 012001.

29. Bowie JH, Brinkworth CS, Dua S. Mass Spectrom Rev. 2002; 21: 87107.

30. Bilusich D, Bowie JH. Mass Spectrom Rev. 2009; 28: 20-34.

31. Liu W-T, Ng J, Meluzzi D, Bandeira N, Gutierrez M, Simmons TL, Schultz AW, Linington RG, Moore BS, Gerwick WH, Pevzner PA, Dorrestein PC. Anal Chem. 2009; 81: 4200-4209.

32. Niedermeyer THJ, Strohalm M. PLOS ONE. 2012; 7: e44913.

33. Suyama TL, Gerwick WH, McPhail KL. Bioorg Med Chem. 2011; 19 : 6675-6701.
Highlights

- $\quad$ First total synthesis of the natural product trichormamide A.

- Extension of the synthesis to a trichormamide $A$ diastereomer.

- Trichormamide A synthesized through a SPPS and in solution cyclization process

- $\quad$ Structures were studied by means of NMR and HRMS 